\title{
Do women with migraine have higher prevalence of temporomandibular disorders?
}

\author{
Mulheres com enxaqueca têm maior prevalência de disfunção temporomandibular?
}

Maria C. Gonçalves ${ }^{1}$, Lidiane L. Florencio ${ }^{1}$, Thaís C. Chaves
,
José G. Speciali $^{2}$, Marcelo E. Bigal $^{3}$, Débora Bevilaqua-Grossi

ABSTRACT | Objectives: The aim of this study was to assess the prevalence of Temporomandibular Disorders (TMD), using the Research Diagnostic Criteria for TMD (RDC/TMD) in women with episodic and chronic migraine (M and $\mathrm{CM}$ ), as well as in asymptomatic women. Method: Sample consisted of 61 women, being 38 with M and 23 with CM, identified from a headache outpatient center; we also investigated 30 women without headaches for at least 3 months (women without headache group - WHG). Assessment of TMD was conducted by a physical therapist who was blind to the headache status. Results: The prevalence of TMD, assessed through the RDC, was 33.3\% in the WHG, $86.8 \%$ in the M group and $91.3 \%$ of the CM group. Differences were significant when comparing M and CM groups with WHG $(\mathrm{p}<0.001)$, but not when comparing $\mathrm{M}$ and $\mathrm{CM}(\mathrm{p}>0.05)$ as well as higher risk for TMD [odds ratio $(\mathrm{OR})=3.15,95 \%$ confidence interval (CI) $1.73-5.71$ and $\mathrm{OR}=3.97,95 \%$ CI 1.76-8.94]. Conclusion: Women with migraine are more likely to have muscular and articular TMD, suggesting that both disorders might be clinically associated, which demonstrate the importance of physical therapy assessment in the multidisciplinary team.

Keywords: temporomandibular disorders; orofacial pain; physical therapy; rehabilitation; RDC/TMD.

\section{HOW TO CITE THIS ARTICLE}

Gonçalves MC, Florencio LL, Chaves TC, Speciali JG, Bigal ME, Bevilaqua-Grossi D. Do women with migraine have higher prevalence of temporomandibular disorders? Braz J Phys Ther. 2013 Jan-Feb; 17(1):64-68. http://dx.doi.org/10.1590/ S1413-35552012005000054

RESUMO | Objetivos: Avaliar a presença de disfunção temporomandibular (DTM) usando o Critério Diagnóstico em pesquisa para disfunção temporomandibular (RDC/TMD) em mulheres com migrânea episódica e migrânea crônica (M e MC), bem como em mulheres sem nenhuma cefaleia. Método: A amostra foi composta por 61 mulheres, 38 com M e 23 com MC, selecionadas em um centro terciário de saúde; também foram avaliadas 30 mulheres sem nenhuma cefaleia nos últimos três meses (grupo de mulheres sem cefaleia - MSC). A avaliação da DTM foi realizada por um fisioterapeuta que não tinha conhecimento do diagnóstico das pacientes. Resultados: Por meio do RDC/TMD, a frequência de DTM foi de $33.3 \%$ no grupo MSC, $86.8 \%$ no grupo M e $91.3 \%$ no grupo MC. A diferença foi significativa entre os grupos com migrânea e o grupo MSC $(\mathrm{p}<0.001)$, porém não houve diferença entre os grupos $\mathrm{Me} \mathrm{MC}(\mathrm{p}>0,05)$, bem como maior fator de risco de DTM [odds ratio (OR)=3,15, intervalo de confiança (IC) de 95\% 1,73-5,71 e OR=3,97, IC95\% 1,76-8,94]. Conclusão: Mulheres com migrânea têm maior frequência de DTM muscular e articular, sugerindo que essas condições estão clinicamente associadas, evidenciando a importância do fisioterapeuta na equipe de avaliação multidisciplinar.

Palavras-chave: dor orofacial; fisioterapia; reabilitação; disfunção temporomandibular.

\section{Introduction}

Migraine is an extraordinarily common disorder. It is more prevalent in women, about $18 \%$ in women and $6 \%$ in man. It is most common during the peak productive years, between the ages of 25 and 55 years-old. Migraineurs experience high levels of pain and substantial disability; less than $10 \%$ of migraineurs report that they are able to work or function normally during their headaches ${ }^{1,2}$.
Migraine and temporomandibular disorders (TMD) are chronic disease ${ }^{3-5}$ with shared characteristics, such as the presence, duration and severity of pain, the temporal pattern and the presence of psychiatric comorbidities $^{6,7}$. Furthermore, the severity of TMD often correlates with the severity of migraine headaches ${ }^{8}$.

The association of TMD and frequency of headaches has been well described ${ }^{4,9-11}$, suggesting

\footnotetext{
${ }^{1}$ Department of Biomechanics, Medicine, and Rehabilitation of Locomotor Apparatus, Faculdade de Medicina de Ribeirão Preto, Universidade de São Paulo (FMRP-USP), Ribeirão Preto, SP, Brazil

${ }^{2}$ Department of Neuroscience and Behavioral Sciences, FMRP-USP, Ribeirão Preto, SP, Brazil

${ }^{3}$ Neurologist, North Wales, USA

Received: 08/05/2012 Revised: 08/07/2012 Accepted: 08/14/2012
} 
that both conditions are influenced by similar predisposing factors, or that they share common peripheral and/or central mechanisms ${ }^{10}$. Most studies, however, inferred TMD based only upon their symptoms ${ }^{4}$, and few studies used objective tools for the diagnosis of this condition ${ }^{12,13}$.

The Research Diagnostic Criteria for Temporomandibular Disorders (RDC/TMD) requires a standardized exam, and allows the diagnosis of TMD with three sub-diagnoses: Group I describe the muscular forms of TMD; Group II refers to TMD disk displacement; Group III encompasses TMD with arthralgia, osteoarthritis, and arthroses ${ }^{14}$. The RDC is a well validated tool for the diagnosis and assessment of TMD ${ }^{15}$, with high specificity for most subtypes ${ }^{16,17}$.

Understanding the association between TMD and migraine subtypes is important for several reasons. First, TMDs, joint origin, cause headache per se (headache attributed to TMDs), and this is recognized as a secondary headache by the Second Edition of the International Classification of Headache Disorders $(\text { ICHD-II })^{18}$. Second, TMDs may also exacerbate preexisting primary headaches (e.g. migraine) and individuals with both conditions may suffer an additional burden when compared to those with only one $^{19,20}$. Finally, determine whether the frequency of migraine influences the diagnosis of TMD. Despite physical therapy in headache is little known of the effects musculoskeletal physical therapy practice has been increasingly exploited ${ }^{21,22}$.

Therefore, the aim of this study was to assess the prevalence of TMD, by physical therapist using the RDC/TMD, axis 1, in women with episodic and chronic migraine ( $\mathrm{M}$ and $\mathrm{CM}$ ).

\section{Method}

We assessed 38 women with M, 23 with $\mathrm{CM}$ and 30 women without any type of headache over the past three months (women without headache group - WHG) selected by a physical therapist among the companions of the patients, with age ranging from 20 to 55 years. $\mathrm{M}$ and $\mathrm{CM}$ were diagnosed by a neurologist, according to the Second Edition of the International Classification of Headache Disorders (ICHD-II) ${ }^{18}$, as well as the presence of allodynia. Patients who had used non-steroidal antiinflammatory drugs during the 24 hours proceeding the day of the assessment, with systemic disease or history of facial trauma were excluded from the study. We have excluded patients in a migraine attack or if they report cutaneous allodynia. These exclusions were recommended by RDC/TMD validation project $^{23}$.

The volunteers were consecutively recruited after assessment at the University-based headache outpatient clinic. The M and CM volunteers, as well as their partners were invited to participate in the study and if they agreed to participate, they have signed a consent form. Then the volunteers were allocated in three groups (M, CM and WHG). The assessments on M, CM and WHG were performed by other a physical therapist blinded for the allocation of the groups and trained in the application of the RDC/TMD axis I.

The presence of TMD was assessed using the research diagnostic criteria for temporomandibular Disorders (RDC/TMD) ${ }^{10}$. The RDC/TMD axis I, is a clinical, non-invasive assessment that has been extensively validated and used in research ${ }^{16,17}$. The $\mathrm{RDC} / \mathrm{TMD}$ is a reliable and valid diagnostic research tool developed by a consensus of experts for the development of operational diagnoses for patients with TMD. The clinical examination takes about 30 minutes, which includes the measurement of the mandible range of motion, assessment of joint and muscle pain and palpation for clicks or crepitus on movements of the mandible. Furthermore, 24 sites were assessed for manual establishment of pain thresholds: posterior, middle and anterior temporalis muscle, superior, middle and inferior masseter muscle, posterior mandibular region, submandibular region, lateral/posterior pole of the temporomandibular joint, inside the mouth, lateral pterygoid area and tendon of the temporal muscle were palpated, as described in the RDC/TMD.

This study was approved by the Ethics Committee in Research of Hospital and Clinics School of Medicine at Ribeirão Preto, Universidade de São Paulo (HC-FMRP-USP), Ribeirão Preto, SP, Brazil, No. 9663/2006. All volunteers signed an informed consent form.

\section{Statistical analysis}

The age among groups were compared using Analyses of Variance (ANOVA). Proportions were compared using the $\chi$ test. Two-way ANOVA with Tukey post-test was used to compare the number of tender points and the number of positive diagnoses. Odds ratio (OR) and 95\% confidence intervals (CI) were calculated at a significance level of $5 \%$ to assess the risk factor of presence of temporomandibular dysfunction.

\section{Results}

Our sample consisted of 91 women. The mean age was 39.07 years for WHG, 39.16 years for $\mathrm{M}$ and 38.83 for CM (ANOVA $p>0.05$ ). TMD was diagnosed in $10(33.33 \%)$ women from the WHG, $33(86.8 \%)$ women with $\mathrm{M}$ group and 21 (91.3\%) women with 
Table 1. Prevalence of diagnosis of temporomandibular disorder (TMD) in women with episodic migraine and chronic migraine in relation to women without headache group.

\begin{tabular}{lccccc}
$\begin{array}{c}\text { Without } \\
\text { headache group } \\
\mathbf{n}(\%)\end{array}$ & $\begin{array}{c}\text { Chronic } \\
\text { migraine } \\
\mathbf{n}(\%)\end{array}$ & $\begin{array}{c}\text { ODDS Ratio } \\
(\mathbf{9 5 \%} \mathbf{C I})\end{array}$ & $\begin{array}{c}\text { Without } \\
\text { headache group } \\
\mathbf{n}(\%)\end{array}$ & $\begin{array}{c}\text { Migraine } \\
\mathbf{n}(\%)\end{array}$ & $\begin{array}{c}\text { ODDS Ratio } \\
(\mathbf{9 5 \%} \mathbf{C I})\end{array}$ \\
$20(66.67)$ & $2(8.7 \%)$ & & $20(66.67 \%)$ & $5(13.16 \%)$ & \\
$10(33.33)$ & $21(91.30 \%)^{\dagger}$ & $3.97(1.53-8.94)$ & $10(33.33 \%)$ & $33(86.84 \%)^{\dagger}$ & $3.15(1.73-5.71)$ \\
30 & 23 & & 30 & 38 & \\
\hline
\end{tabular}

Total sample $=91 . \dagger$ Chi-square test $\mathrm{p}<0.05$ compared to without headache group.

Table 2. Subtype of Temporomandibular Disorders (TMD) in individuals with episodic migraine, chronic migraine and in women without headache group.

\begin{tabular}{llll}
\hline & WHG $(\mathbf{n = 3 0})$ & $\mathbf{M}(\mathbf{n = 3 8})$ & $\mathbf{C M}(\mathbf{n = 2 3})$ \\
Groups I & $9(30 \%)^{*}$ & $21(55.26 \%)$ & $12(52.17 \%)$ \\
Groups I+II & 0 & $4(10.52 \%)$ & $2(8.70 \%)$ \\
Groups I+III & $1(3.33 \%)$ & $8(21.05 \%) *$ & $3(13.04 \%)$ \\
Groups I+II+III & 0 & $1(2.63 \%)$ & $4(17.39 \%) *$ \\
\hline
\end{tabular}

WHG=women without headache group; M=episodic migraine; $\mathrm{CM}=$ chronic migraine. Total sample $=91 .(\mathrm{p}>0.05),{ }^{*}$ Chi-square test $(\mathrm{p}<0.05)$.

CM group. TMD was significantly more prevalent in women with $\mathrm{M}$ and $\mathrm{CM}$ groups, as compared to WHG (Table 1).

As compared with women without headache, women with $\mathrm{M}$ and $\mathrm{CM}$ were significantly more diagnosed with TMD and also presented higher risk for $\mathrm{TMD}(\mathrm{OR}=3.15,95 \% \mathrm{CI} 1.73-5.71$ and $\mathrm{OR}=3.97$, 95\%CI 1.76-8.94) (Table 1).

Diagnoses of group I were the most prevalent in all groups. Mixed diagnoses (I+II and I+II+III) were observed only in individuals with migraine, and were more common in CM than in $\mathrm{M}$ group. Diagnoses of groups I+III were observed in the three groups, but were more prevalent in the $\mathrm{M}$ group than in the other groups. TMDs from groups II and III were not observed (Table 2).

Women with $\mathrm{M}$ and $\mathrm{CM}$ had a significantly higher number of TMD diagnoses, as compared to WHG. No between-group differences were observed in those with $\mathrm{M}$ vs. CM. The number of sites that presented muscle pain on palpation was significantly higher in individuals with $\mathrm{M}$ and $\mathrm{CM}$, as compared to $\mathrm{WHG}$, but no between-group difference was observed between the $\mathrm{M}$ and $\mathrm{CM}$ groups. No differences were observed regarding the number of sites that had joint pain on palpation (Table 3 ).

\section{Discussion}

Our sample consisted of patients from a tertiary outpatient clinic, which could explain the higher
Table 3. Mean and standard deviation of different number of diagnoses. according to the number of RCD/TMD, muscular tender points (maximum $=20)$ and number of articular tender points (maximum $=4$ ).

\begin{tabular}{lccc}
\hline \multicolumn{1}{c}{ Groups } & $\begin{array}{c}\text { Number of } \\
\text { RDC/TMD } \\
\text { Diagnoses }\end{array}$ & $\begin{array}{c}\text { Number of } \\
\text { muscular } \\
\text { tender points }\end{array}$ & $\begin{array}{c}\text { Number of } \\
\text { articular } \\
\text { tender points }\end{array}$ \\
WHG $(\mathrm{n}=30)$ & $0.45 \pm 0.72 *$ & $7.03 \pm 5.52 *$ & $0.63 \pm 0.96$ \\
$\mathrm{M}(\mathrm{n}=38)$ & $1.47 \pm 1.05$ & $14.73 \pm 5.75$ & $1.78 \pm 1.41$ \\
$\mathrm{CM}(\mathrm{n}=23)$ & $1.87 \pm 1.15$ & $16.21 \pm 3.89$ & $1.78 \pm 1.16$ \\
\hline
\end{tabular}

WHG=women without headache group; M=episodic migraine; $\mathrm{CM}=$ chronic migraine. Total sample=91, *ANOVA two-Way $(\mathrm{p}<0.05)$.

frequency of TMD diagnoses in all groups, although more frequently in individuals with $\mathrm{M}$ and $\mathrm{CM}$. In our study women without headache have a prevalence of $33.3 \%$ of TMD, in agreement with other clinical studies that have reported higher prevalence rates (45 to 50\%) TMD diagnoses ${ }^{24}$ the signs and symptoms of $\mathrm{TMD}^{25}$.

Women with migraine have not only a higher prevalence of TMD, but also a higher risk factor for developing the disease. Other studies that used the RDC/TMD also reported the association of TMD and headaches ${ }^{12,13}$, as similar findings were observed for signs and symptoms of TMD and headaches ${ }^{4}$. The prevalence of TMD was not different between $\mathrm{M}$ and $\mathrm{CM}$, suggesting that TMD reflects the disease itself, not disease severity in terms of frequency and the central sensitization mechanisms of neurons in migraine patients, independently of being chronic or not, could explain such findings.

Similar to other study ${ }^{13}$, most individuals with TMD (from the three groups) presented myofascial pain, although the prevalence was higher in $\mathrm{M}$ and CM vs. WHG $(\mathrm{p}<0.05)$. Women with $\mathrm{M}$ and $\mathrm{CM}$ had significantly higher number of diagnoses from the muscular group (group I) as compared to disk displacements (group II) and diagnoses of arthralgia, osteoarthritis and osteoarthrosis (group III) suggesting that muscular and mixed TMD could be strictly associated with headaches.

We have not observed individuals with diagnoses from groups II and III isolated, and although mixed 
diagnoses (I+II, I+III and I+II+III) were verified in the three groups, it was more common in $\mathrm{M}$ and $\mathrm{CM}$ groups. In a recent study, Gonçalves et al. ${ }^{26}$ suggested that the magnitude of TMD was associated with migraine severity and individuals reporting at least one TMD symptom were more likely to experience headache syndromes than individuals without TDM.

Three hypotheses may be suggested to explain the relationship between migraine and TMD. First, mechanisms of peripheral and central sensitization, involved in pain perception and pain transmission ${ }^{7}$ and activated in migraine, may spread the pain from the head to the craniocervical region ${ }^{27}$, decreasing the threshold for pain in the face; accordingly, individuals would have migraine with pain in the temporomandibular region (masticatory muscles and temporomandibular joint) but not true TMD. Second, mechanisms of central sensitization would be of importance for the pathophysiology and onset of both, migraine and TMD. Third, TMD or migraine may aggravate and perpetuate the other, and individuals with migraine may have their headaches worsened by the coexistence of TMD, being the opposite true as well ${ }^{26}$.

Physical therapy assessment is important, as women with migraine had significantly higher number of tender points, as compared to women without headache. Similar findings were observed by other authors ${ }^{12}$, suggesting that headache is associated with musculoskeletal problems, such as myalgia and myofascial pain dysfunction syndrome ${ }^{19,20}$, making necessary the presence of physical therapist in the multidisciplinary team in the cephalic evaluation ${ }^{20,28}$.

Patients with migraine and TMD have widespread dysfunction of the nociceptive system ${ }^{7}$ and cutaneous allodynia is more common in individuals with migraine and TMD ${ }^{29}$, when compared to migraineurs without TMD, suggesting the importance of both conditions on trigeminal sensitization. Indeed, both migraine and TMD predispose to allodynia, and the presence of one (e.g. migraine) may, trough the phenomena of central sensitization, predispose to $\mathrm{TMD}^{27}$. Although we excluded patients with these conditions, it was common during migraine attacks, therefore, it is possible that many migraine patients have this sensory dysfunction.

Despite the use of the gold standard for the TMD diagnosis (RDC/TMD), we have to be cautious to interpret our results. First, the RCD/TMD seems to over-diagnose problems of group I, and a possible explanation could be to the disproportion between the number of examined sites on muscles (20 sites) and joints (4 sites). It may be why the muscular groups are overrepresented in relation to the joint groups ${ }^{30}$, yielding to the over-diagnosis of myofascial pain ${ }^{31}$. One alternative to correct this limitation of the RDC/
TMD would be to exclude muscle sites that are difficult to access (lateral pterygoid, temporal tendon, posterior region of the mandible, and submandibular region $)^{32}$. Sensitivity analyses were performed by removing these tree muscle points from data and there were no differences in diagnostic rates.

The increased sensitivity in the pericranial muscles (including the masticatory muscles) of migraineurs suggest the importance and needs of multidisciplinary assessments, including the physical therapist. Furthermore, headache patients may also benefit from TMD examination, especially those who do not respond to the usual headache management.

\section{Conclusion}

TMD and migraine are clinically associated. Women with migraine are more likely to have TMD when compared to women without headache, both for the muscular and joint diagnoses. They are also more likely to have increased number of tender points, highlighting the importance of the physical therapist in the assessment of these patients.

\section{Acknowledgements}

The Fundação de Amparo a Pesquisa do Estado de São Paulo, Brazil (FAPESP process 2007/5753-0) for the master degree scholarships.

\section{References}

1. Lipton RB, Stewart WF, Diamond S, Diamond ML, Reed M. Prevalence and burden of migraine in the United States: data from the American Migraine Study II. Headache. 2001;41(7):646-57.

2. Queiroz LP, Peres MFP, Piovesan EJ, Kowacs F, Ciciarelli MC, Souza JA, et al. A nationwide population-based study of migraine in Brazil. Cephalalgia. 2009;29(6):642-9.

3. LeResche L. Epidemiology of temporomandibular disorders: implications for the investigation of etiologic factors. Crit Rev Oral Biol Med. 1997;8(3):291-305.

4. Ciancaglini R, Radaelli G. The relationship betwwenn headache and symptoms of temporomandibular disorder in the general population. J Dent. 2001;29(2):93-8.

5. Lipton RB, Bigal ME. Headache as a real disease. Headache. 2008;48(5):707-10.

6. Merrill RL. Orofacial pain mechanisms and their clinical application. Dent Clin North Am. 1997;41(2):167-88.

7. Sarlani E, Greenspan JD. Why look in brain for answers to temporomandibular disorder pain? Cells Tissues Organs. 2005;180(1):69-75.

8. Liljeström MR, Jämsä A, Le Bell Y, Alanen P, Anttila P, Metsähonkala L, et al. Signs and symptoms of temporomandibular disorders in children with different types of headache. Acta Odontol Scand. 2001;59(6):413-7. 
9. Rantala MA, Ahlberg J, Suvinen TI, Nissinen M, Lindholm H, Savolainen A, et al. Temporomandibular joint related painless symptoms, orofacial pain, neck pain headache, and psychosocial factors among non-patients. Acta Odonltol Scand. 2003;61(4):217-22.

10. Storm C, Wänman A. Temporomandibular disorders, headache, and cervical pain among females in a Sami population. Acta Odontol Scand. 2006;64(5):319-25.

11. Moreno BGD, Maluf SA, Marques AP, Crivello-Junior O. Clinical and quality-of-life assessment among women with temporomandibular disorder. Rev Bras Fisioter. 2009;13(3):210-4. http://dx.doi.org/10.1590/ S1413.355.5200900.500.0028

12. Glaros AG, Urban D, Locke J. Headache and temporomandibular disorders: evidence for diagnostic and behavioural overlap. Cephalalgia. 2007;27(6):542-9.

13. Ballegaard V, Thede-Schmidt-Hansen P, Svensson P, Jensen R. Are headache and temporomandibular disorders related? A blinded study. Cephalalgia. 2008;28(8):832-41. http://dx.doi.org/10.1111/j.1468-2982.2008.01597

14. Dworkin SF, LeResche L. Research diagnostic criteria for temporomandibular disorders: review, criteria, examinatios and specificatios, critique. J Craniomandib Disord. 1992;6(4):301-5.

15. Chaves TC, Oliveira AS, Bevilaqua-Grossi D. Principais instrumentos para avaliação da disfunção temporomandibular, parte II: critérios diagnósticos; uma contribuição para a pratica clínica e de pesquisa. Fisioter Pesqui. 2008;15(1):101-6.

16. Dworkin SF, Sherman J, Mancl L, Ohrbach R, LeResche L, Truelove E. Reliability, validity, and clinical utility of the research diagnostic criteria for temporomandibular disorders Axis II Scales: depression, non-specific physical symptoms, and graded chronic pain. J Orofac Pain. 2002;16(3):207-20.

17. Schmitter M, Gabbert O, Ohlmann B, Hassel A, Wolff D, Rammelsberg P, et al. Assessment of the reliability and validity of panoramic imaging for assessment of mandibular condyle morphology using both MRI and clinical examination as the gold standard. Oral Surg Oral Med Oral Pathol Oral Radiol Endod. 2006;102(2):220-4.

18. Subcomitê de classificação das cefaléias da Sociedade Internacional de Cefaléias. Classificação international das cefaléias. 2. ed. Trad. Sociedade Brasileira de Cefaléias. São: Segmento Farma Editores; 2004.

19. Bevilaqua-Grossi D, Lipton RB, Bigal ME. Temporomandibular disorders and migraine chronification. Curr Pain Headache Rep. 2009;13(4):314-8.

20. Bevilaqua-Grossi D, Chaves TC, Gonçalves MC, Moreira VC, Canonica AC, Florencio LL, et al. Pressure pain threshold in the craniocervical muscles of women with episodic and chronic migraine: a controlled study. Arq Neuropsiquiatr. 2011;69(4):607-12.

21. Fernández-de-las-Peñas C, Cleland JA, Palomequedel-Cerro L, Caminero AB, Guillem-Mesado A, Jiménez-García R. Development of a clinical prediction rule for identifying women with tensiontype headache who are likely to achieve short-term success with joint mobilization and muscle trigger point therapy. Headache. 2011;51(2):246-61. http://dx.doi. org/10.1111/j.1526-4610.2010.01789.x
22. Morelli JGS, Rebelatto JR. The effectiveness of manual therapy in individuals with headaches, with and without cervical degeneration: analysis of six cases. Rev Bras Fisioter. 2007;11(4):325-9. http://dx.doi.org/10.1590/ S1413.355.5200700.040.0013

23. Schiffman E, Ohrbach R, Truelove E. RDC/TMD validation project. 2010. Cited: 26/11/03. Available from: http://www.rdc-tmdinternational.org/OtherResources/ ResearchProtocols.aspx

24. Casanova-Rosado JF, Medina-Solís CE, VallejosSánchez AA, Casanova-Rosado AJ, Hernández-Prado B, Ávila-Burgos L. Prevalence and associated factors for temporomandibular disorders in a group of Mexican adolescents and youth adults. Clin Oral Investig. 2006;10(1):42-9.

25. Bonjardim LR, Lopes-Filho RJ, Amado G, Albuquerque RLC, Gonçalves SRJ. Association between symptoms of temporomandibular disorders and gender, morphological occlusion, and psychological factors in a group of university students. Indian J Dent Res. 2009;20(2):190-4.

26. Gonçalves DAG, Speciali JG, Jales LCF, Camparis CM, Bigal ME. Temporomandibular symptoms, migraine, and chronic daily headaches in the population. Neurology. 2009;73(8):654-6. http://dx.doi.org/10.1212/ WNL.0b013e3181b389c2

27. John MT, Dworkin SF, Mancl LA. Reliability of clinical temporomandibular disorders diagnoses. Pain. 2005;118(1-2):61-9. http://dx.doi.org/10.1016/j. pain.2005.07.018

28. Florêncio LL, Pereira PA, Silva ER, Pegoretti KS, Gonçalves MC, Bevilaqua-Grossi D. Agreement and reliability of two non-invasive methods for assessing cervical range of motion among young adults. Rev Bras Fisioter. 2010;14(2):175-81. http://dx.doi.org/10.1590/ S1413.355.5201000.500.0011

29. Bevilaqua-Grossi D, Lipton RB, Napchan U, Grosberg B, Ashina S, Bigal ME. Temporomandibular disorders and cutaneous allodynia are associated in individuals with migraine. Cephalagia. 2010;30(4):425-32. http://dx.doi. org/10.1111/j.1468-2982.2009.01928.x

30. Steenks MH, De Wijer A. validity of the Research Diagnostic Criteria for Temporomandibular Disorders Axis I clinical and research settings. J Orofac Pain. 2009;23(1):9-16; discussion 17-27.

31. List T, Dworkin SF. Comparing TMD diagnoses and clinical findings at Swedish and US TMD centers using research diagnostic criteria for temporomandibular disorders. J Orofac Pain. 1996;10(3):240-53.

32. Steenks MH, de Wijer A. Validity of the Research Diagnostic Criteria for Temporomandibular Disorders Axis I clinical and research settings. Validity of the Research Diagnostic Criteria for temporomandibular disorders axis i in clinical and research settings. J Orofac Pain. 2009;23(1):9-16; discussion 17-27.

\section{Correspondence}

\section{Maria Claudia Gonçalves}

Universidade de São Paulo, Faculdade de Medicina de Ribeirão Preto, Departamento de Biomecânica, Medicina e Reabilitação do Aparelho Locomotor, Av. Bandeirantes, 3900

CEP 14049-900, Ribeirão Preto, SP, Brasil

e-mail: mcgfisio@yahoo.com.br 